\title{
Diseño gráfico y etiquetas en empresas murcianas
}

Pedro Antonio Galindo Valero - Rosa María García López² - María Gracia Ruiz Llamas ${ }^{3}$

RECIBIDO: 16.02.2018 / ACEPTADO: 24.03.2018

\section{Resumen}

El diseño gráfico, entre otras funciones, da a conocer un producto en los mercados y la etiqueta facilita el proceso de difusión, convirtiéndose precisamente en la imagen e identificación de éste.

El objetivo fundamental de nuestro trabajo, está en el conocimiento de determinados diseños de una época, observando el proceso de desarrollo y evolución de la misma. Al mismo tiempo que contribuimos a conservar y difundir ese patrimonio gráfico de un referente territorial poco conocido en este ámbito.

Revisamos el diseño gráfico de etiquetas, concretamente en la industria pimentonera, analizando para ello los siguientes aspectos: tipos de etiqueta, funciones y características generales.

Palabras clave: pimentón, diseño gráfico, etiqueta.

\section{Abstract}

Graphic design, among other marketing tools, makes a product known in the market, being the label the key to the process of the product diffusion, thus becoming, in point of fact, its image and brand mark.

The main goal of our work is identifying a variety of designs in a period of time, observing their process of development and evolution. At the same time, intend to contribute to preserve and disseminate this graphic heritage of a little-known territorial reference in this field.

We review and reflect on the graphic design of labels, particularly in the paprika industry, looking into the following aspects: the types of labels, their functions and general features.

Keywords: paprika, graphic design, label.

\footnotetext{
1 Licenciado en Bellas Artes por la Universidad de Granada. Doctor en Bellas Artes por la Universidad de Granada. Profesor Funcionario de Carrera, Cuerpo de Profesores de Enseñanza Secundaria, Especialidad de Dibujo. IES Luis Manzanares, Torre Pacheco (Murcia). Correo-e: artegalva@hotmail.com.

2 Doctora en Bellas Artes y Profesora Titular de la Universidad de Murcia.

3 Doctora en Bellas Artes y Profesora Titular de la Universidad de Granada.
} 
"La etiqueta hoy en su definición industrial y comercial es la presentación, el vestido, la dignificación del envase que la lleva, sin desechar las funciones de identificación, personalización, descripción y uso del contenido, etc.”

A.L. Cervera Fantoni ${ }^{4}$

\section{INTRODUCCIÓN}

El proceso investigador y visión creativa del desarrollo y evolución de la etiqueta nos ha llevado a centrarnos en una parte de la industria murciana del siglo XX. La industria pimentonera de manera específica, en el contexto geográfico del diseño gráfico y la etiqueta en la misma zona respecto a su ámbito global.

Partimos de un recorrido breve sobre la propia época modernista y su industria, el diseño y los artistas que intervenían, fundamentalmente centrado en Murcia, aunque en el contexto del resto del país.

Creemos importante, por su repercusión, comenzar citando dichos inicios y su evolución hasta la actualidad. De este modo, para llevar a cabo un análisis cronológico del desarrollo del diseño gráfico en la industria murciana en el siglo XX, plantearemos dicho recorrido histórico en diferentes etapas:

- Época Modernista y auge de la industria para impresión.

- Diseño de etiquetas y envoltorios.

- Artistas más destacados y sus diseños:

- Primera mitad siglo XX. (1899-1949)

- Segunda mitad siglo XX. (1950-1999)

\section{OBJETIVOS}

La observación de la evolución y el proceso de desarrollo de la etiqueta, a través del conocimiento de diversos tipos de diseño en diferentes épocas, será nuestro objetivo principal.

Se revisará el diseño gráfico de etiquetas de la industria conservera murciana, y especialmente la pimentonera. Además se analizarán las funciones y tipos de etiqueta.

\section{DISEÑO GRÁFICO \\ ÉPOCA MODERNISTA Y AUGE DE LA INDUSTRIA PARA IMPRESIÓN}

La referencia cronológica de nuestro estudio es el año 1899, año en que la Cámara Oficial de Comercio, Industria y Navegación de Murcia comienza su andadura.

4 CERVERA FANTONI, A.L. Envase y embalaje. La venta silenciosa (2a ed.), ESIC, Barcelona 2003 
Consideramos necesario especificar que el término Modernismo tuvo diferentes apelativos y detalles particulares en otros países del entorno europeo: Art Nouveau, Sezessión (Secesión de Viena, Secesión de Múnich), Jugendstil, Floreale, Liberty, etc. Pero también existieron sus propios matices locales, tales como: Modernismo catalán, Modernismo en Cartagena y La Unión, Modernismo canario, etc.

En 1899, cuando se produce el cambio de siglo, la economía de Murcia se basa principalmente en la agricultura y su modo de vida, detectándose puntos en la geografía regional, donde hay un pequeño avance; tanto en los pueblos y zonas circundantes a la capital murciana como en Cartagena y La Unión. Salen a la luz contrastes y signos de cambio, y ejemplo de ello es la creación de la primera industria conservera generada por J. Esteva en 1897 en Alcantarilla ${ }^{5}$. Otro fenómeno que afectó a este desarrollo industrial se plantea en el año 1900. Se produjeron cambios notables por la industria minera, concretamente en Cartagena y La Unión. Pero el auténtico impulso de la industria de impresión será en el sector de la conserva, germen que transformará la economía regional en el siglo XX.

Pero estos conceptos señalados sólo matizan ciertos aspectos, ya que indiscutiblemente surgen influencias de las interpretaciones de otras zonas. Si tuviésemos que señalar puntos geográficos importantes para destacar el desarrollo del diseño gráfico en España, tal y como lo conocemos hoy, podríamos optar por diversas opciones según los aspectos a señalar. En términos generales, destacaríamos: Barcelona, Madrid y Zaragoza, así como las grandes ciudades industriales con puerto, como Cádiz, Málaga o Valencia.

A través de Barcelona llega a España la influencia modernista de Francia, como comenta Enric Satué ${ }^{\text {. Pero }}$ sería en su área metropolitana donde hubo un importante desarrollo del diseño gráfico en general. Aunque la máxima calidad en el etiquetado se genera en Cádiz y Málaga, cuyos puertos, gracias a la industria de la zona (producción y exportación de vinos en Cádiz, Jerez y Puerto de Santa María, comercialización de la pasa e industria del vino de Málaga) fomentaron el desarrollo del diseño gráfico destinado a la etiqueta ${ }^{7}$. En Cádiz, la calidad de los envases de la industria conservera de pescado se desarrolla para hacer frente a la producción inglesa, cuya escasa calidad falsifica su origen indicando que proceden de Cádiz. Por su parte, más prestigio aún que el vino de Málaga durante el siglo XIX, la industria de la pasa requiere una calidad máxima del envase como producto de élite que se exporta a todo el mundo. Ello requiere que se contraten a los primeros litógrafos alemanes desde el miso inicio de esta técnica a finales del siglo XVIII, al mismo tiempo que se envían allí a profesionales locales de la impresión para ser formados en esta nueva técnica que proporciona un colorido y calidad de impresión lejos de los procedimientos anteriores.

En ambos casos, es importante destacar que la industrialización de las ciudades fue casi en paralelo al desarrollo de la industria del diseño gráfico. Éstas tenían establecidas sus empresas gráficas dando servicios a los empresarios.

5 HERVÁS AVILÉS, J.M. Diseño Gráfico en Murcia (1899-1999), Cámara Oficial de Comercio, Industria y Navegación de Murcia, 1999.

6 SATUÉ, E. El diseño gráfico en España. Historia de una forma comunicativa nueva. Alianza Editorial, Madrid 1997.

7 DEL RÍO FERNÁNDEZ, P. Litografía, creación y producción para la gráfica de los frutos selectos de Málaga (tesis doctoral), Universidad de Málaga, 2010. 
En el caso de Murcia, es en Cartagena y La Unión, donde se detectó una mayor concentración de imprentas y talleres. Posteriormente, debido al auge de la industria en Murcia, fundamentalmente la conserva y el pimentón, las imprentas irán estableciéndose poco a poco.

La historia del diseño gráfico en España señala una etiqueta como referente, la realizada por el suegro de Vicente Bosh: Tomás Salas (aunque otras teorías desmienten esta afirmación, tal y como comprobamos en "La verdadera historia del Anís del Mono $\left.{ }^{8 "}\right)$, que no es otra que la de "Anís el Mono".

Dicha etiqueta supondría un antes y un después en el diseño de etiquetas, pues los estilos anteriores tenían una cierta influencia, sobre todo sus orlas y tipografías, de la corriente Arts and Crafls, cuyo exponente máximo fue William Morris (1834-1896). Un claro referente de este paso fue el modernismo catalán, que igualmente se extiende al resto de España.

Una anécdota curiosa, de la marca registrada por Vicente Bosh y su hermano el 14 de marzo de 1892, es que en el diseño de las primeras etiquetas (fig. 1) apreciamos un error ortográfico, "destilación", que se ha conservado sucesivamente (véase figs. 1 y 2 ).

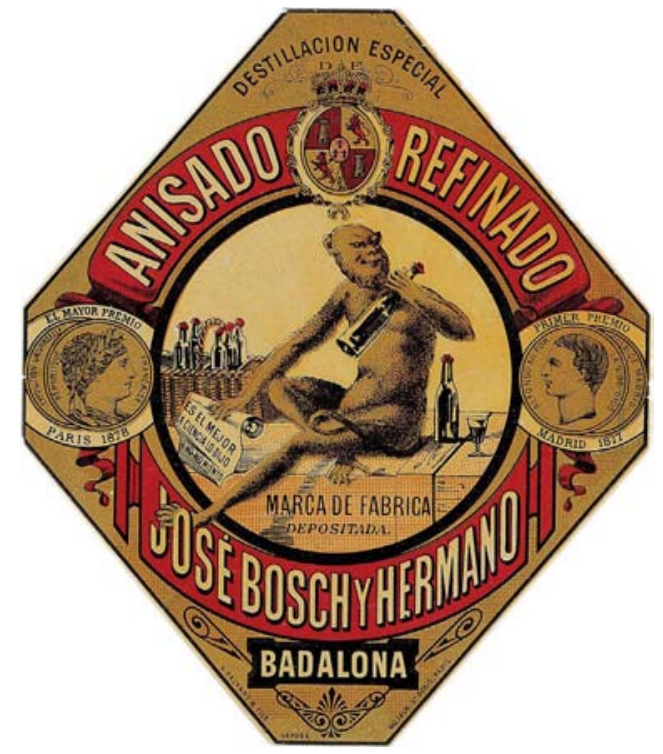

Fig.1. Anís del Mono. José Bosh y hermano. Badalona, 1890-1910. Cromolitografía.

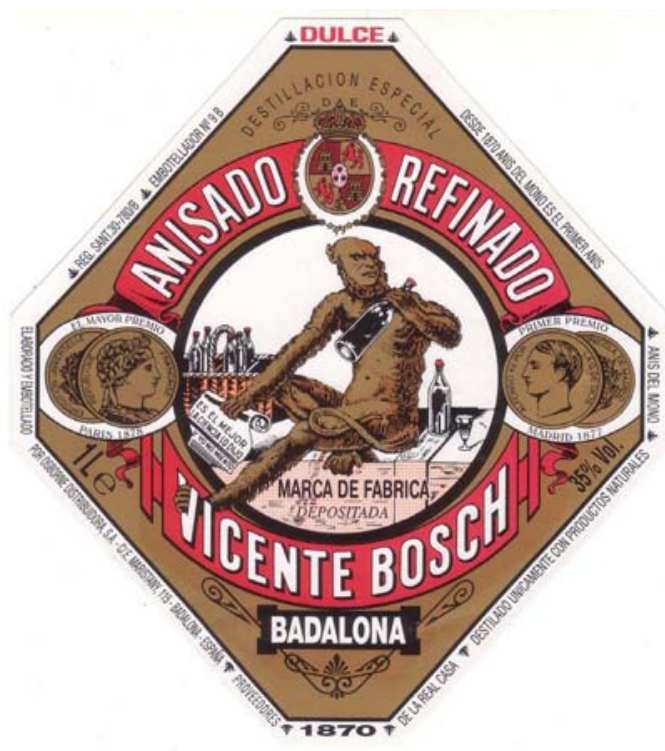

Fig.2. Anís del Mono, etiqueta actual.

El Art Nouveau, Sezessión (Viena y Munich), etc. a finales del siglo XIX, marca influencias que son absorbidas por artistas de diferentes países, que paulatinamente llevarían su espíritu a otros campos, como el de la

8 La verdadera historia del Anís del Mono. <http://manuelblascinco.blogspot.com.es/2015/10/la-verdadera-historia-del-anis-del-mono.html > (11.02.2018)

9 Cuya botella, desde que fuese registrada como marca gráfica el 29 de diciembre de 1899, ha sido plasmada por diversos artistas a lo largo de la historia, tales como Juan Gris, Dalí, Picasso o Diego Rivera. Ha aparecido en películas como No habrá paz para los malvados o El Padrino. 
etiqueta, tal y como afirma Margarita E. Saloma": "Desde el inicio del siglo XX los desarrollos experimentados en el diseño de carteles se extendieron a las tarjetas postales, etiquetas adhesivas, estampillas..."

En la Región de Murcia los primeros empresarios, tanto del sector pimentonero como de la conserva hortofrutícola, encargaban los diseños e impresión a imprentas y talleres cercanos a las grandes capitales, con el ánimo de incorporar nuevas ideas, tal como afirma Ruiz Llamas, M.G. ${ }^{11}$ : "No desfallecían por hallar nuevas formas de expresión y producían sus obras en medio de un animado intercambio de ideas".

De este modo, algunas de las primeras litografías para latas de pimentón fueron encargadas a empresas andaluzas, como es el caso de "Litografía Hurtado" de Jerez y otras empresas litográficas catalanas y alicantinas. Ello se constata igualmente en algunas latas con la etiqueta reproducida por la litográfica $\mathrm{G}$. de Andreis, de Badalona (fig. 3).

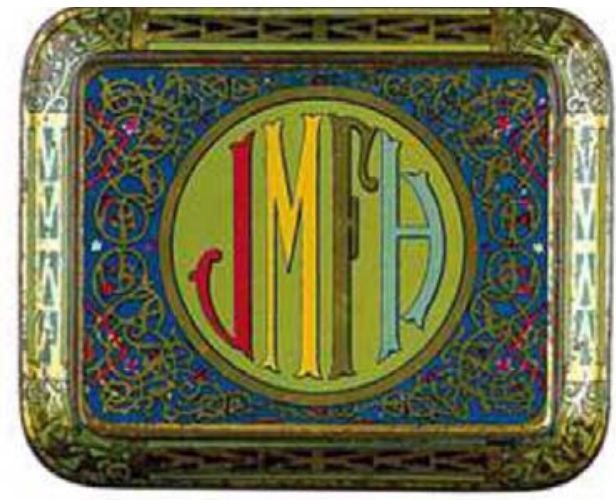

Fig. 3. La Odalisca. Tapadera de envase metálico para pimentón puro, h. 1919. José María Fuster Hernández, Espinardo, Murcia. Ilustración de G. Camas. Litografía G. De Andreis, M.E. Badalona. 16 × 10,5 × $8 \mathrm{~cm}$.

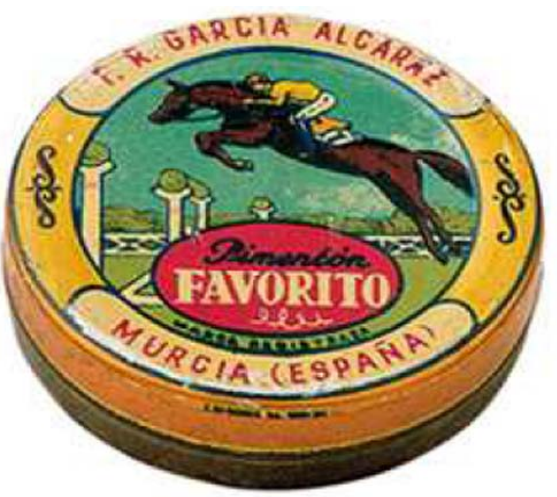

Fig. 4. Favorito. Caja metálica para muestra de pimentón, h. 1950. F.R. García Alcaráz, Murcia. Litografía G. de Andreis. Badalona. Diámetro $5,5 \mathrm{~cm}$.

En esta época existían diversas empresas importantes en el sector, en diferentes puntos de la geografía regional, no sólo en la capital murciana, lo que reflejaba claramente la expansión del sector conservero y pimentonero, que no se centraba solamente en una comarca o zona específica, como las empresas de Juan Navarro en Espinardo o la de Félix Reverte en San Pedro del Pinatar.

Es necesario aclarar, que estas empresas no se limitaban al sector conservero y pimentonero, sino que se dedicaban también a la exportación de frutas y la minería, entre otras actividades. Por lo tanto, cabe destacar empresas como E. Fajón y La Madrileña, que fueron imprentas importantes en la época en las ciudades de Cartagena y La Unión, respectivamente, principalmente dedicadas a la minería. Empresas como la Litografía Pagán y posteriormente La Artística, de Carmelo Bueno, serían las primeras empresas en la capital Murciana, especializadas en la litografía y cromolitografía respectivamente. Esta especialización de las más modernas técnicas gráficas consigue que los encargos no deban recurrir a empresas de otras regiones de España.

10 SALOMA RAMíREZ, M.E. Historia del Diseño Gráfico, London University, México 2006.

11 RUIZ LLAMAS, M.G. La ilustración gráfica en periódicos y revistas de Murcia: 1920-1950, Universidad de Murcia, 1992. 
A pesar de algunos avances de estilo artístico, introducidos en Barcelona, Valencia o Sevilla, durante las dos primeras décadas del siglo XX se continúan aplicando en Murcia orlas y tipografías de influencia del XIX, junto con algunos elementos más modernos. Empresas como La Odalisca (fig. 5) y Tonita (fig. 6) ejemplifican dicha afirmación, a pesar de encargar sus envases en lugares tan diferentes como Badalona y Murcia.

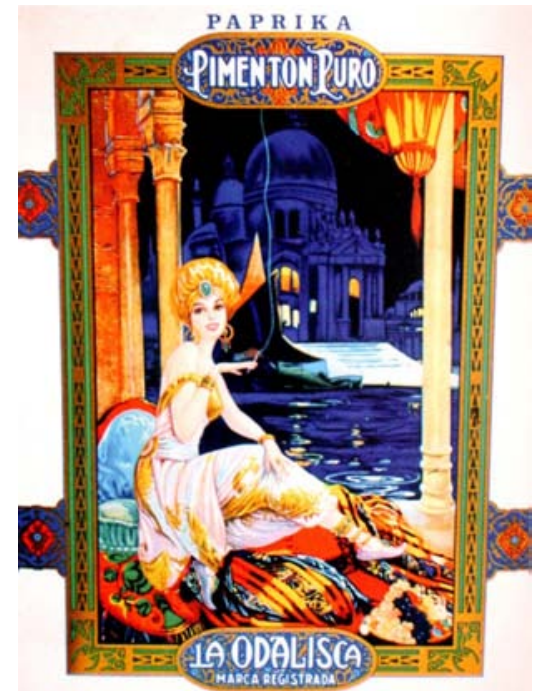

Fig. 5. La Odalisca. Envase metálico para pimentón puro, h. 1919. José María Fuster Hernández. Espinardo. Murcia llustración de G. Camas. Litografía G. De Andreis, M.E. Badalona. 16 × 10,5 x $8 \mathrm{~cm}$

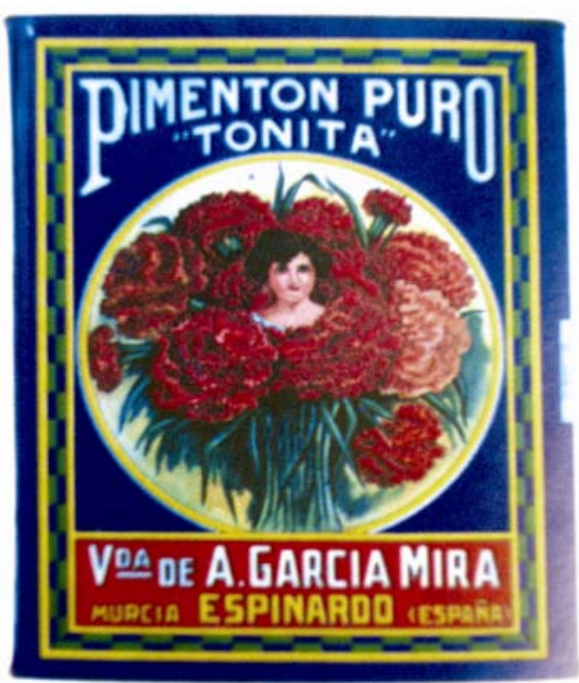

Fig. 6. Tonita. Envase metálico para pimentón puro, h. 1925. Vda. de A. García Mira.

Espinardo. Murcia. Litografía Alemán, Murcia. $32,5 \times 25 \times 19,5 \mathrm{~cm}$.

Este diseño al que veníamos haciendo referencia, de orlas y tipografía decimonónica, se puede apreciar también en impresos comerciales y en la publicidad de la prensa de la época (figs. 7.1 y 7.2).

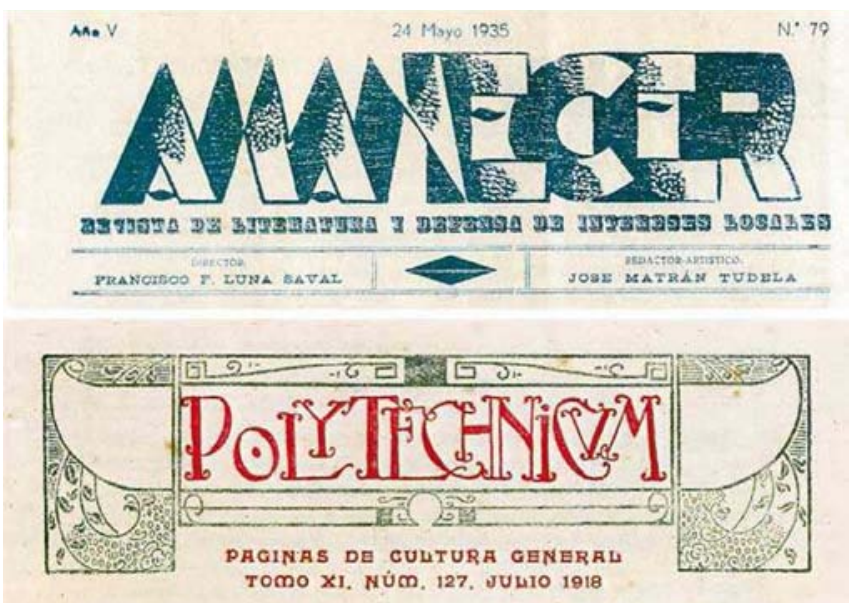

Fig. 7. Ruiz Llamas, M.G. (1991). Cabecera de la revista de medicina, ciencias y cultura general Polytechnicum, carátula de la revista de literatura Amanecer, 1935. Diseños de Gil de Vicario.

La neutralidad de España durante la primera guerra mundial, favorece notablemente a la industria española, así como a la incipiente industria de la región. De este modo, muchas empresas litográficas y otras imprentas 
de la región tuvieron un gran avance, y surgiendo muchas otras, como es el caso de la Litografía Alemán (figs. 8 y 9). Avanzan los modelos tipográficos, respecto a los tradicionales, y se va hacia una nueva evolución del grafismo.

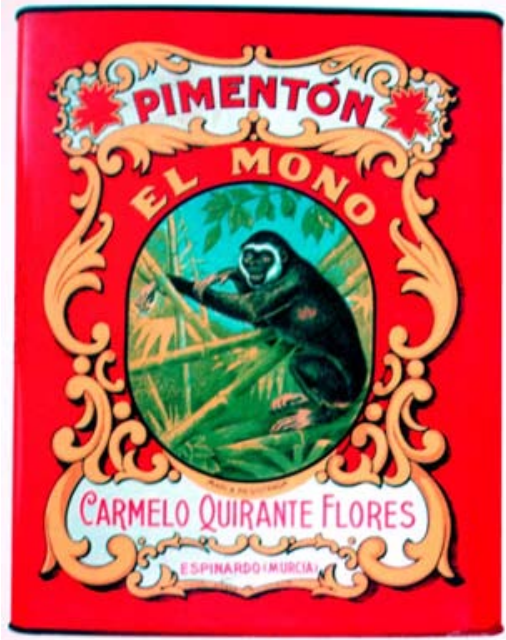

Fig. 8. El Mono. Envase metálico para pimentón, h. 1910. Carmelo Quirante Flores. Espinardo. Murcia. Litografía Manuel Alemán. 32 x 25 x 19,5 cm.

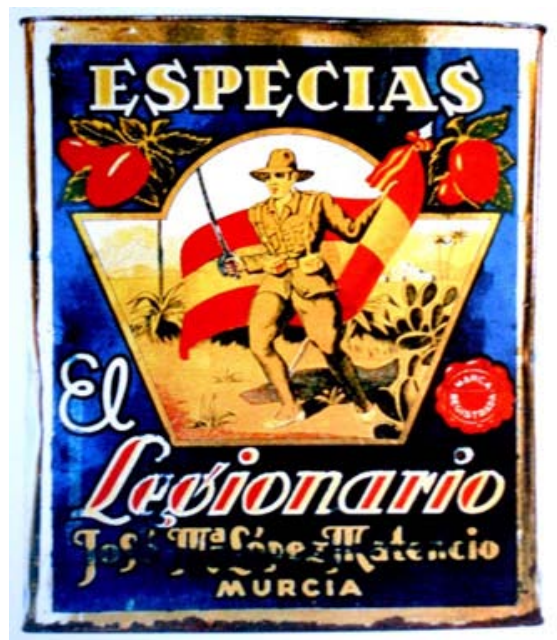

Fig. 9. El Legionario. Envase metálico para pimentón, h. 1925. José María López Matencio. Exportador de pimentón y azafranes. Murcia. Litografía Manuel Alemán. 32,5 x 24,2 x $18,4 \mathrm{~cm}$.

Empresas como Litográfica M. Alemán (hasta 2010 en que cesó su actividad) han continuado hasta la actualidad con estampaciones de época, cuya finalidad no es otra que el comprador asocie la pervivencia de la imagen gráfica, a pesar del paso del tiempo, a la calidad del producto que contiene.

\section{DISEÑO DE ETIQUETAS}

Los desarrollos experimentados en etiquetas, precintos, etc. fomentaron en Alemania una estética refinada para anunciar los productos. En Berlín, los diseñadores restringen la imagen al objeto que se estaba anunciando, con algunas palabras referentes al mismo, y la marca del fabricante. Ello atendía a la influencia que en aquellos momentos estaba ejerciendo, en el diseño, un establecimiento berlinés, la imprenta Hollerbaum und Schmidt $(1914)^{12}$.

La $1^{\text {a }}$ Guerra Mundial potencia el diseño gráfico, que pretende llegar a informar rápida, económica y directamente. En Alemania, con la aplicación de la nueva tipografía "Neue Typographie", se había aprendido a enfatizar el significado de las palabras en espacios en blanco. Es un hecho, como otros, incorporado por la directa participación de los artistas con las empresas, y la aportación que estos hicieron empleando conceptos y aspectos relacionados con las vanguardias del momento, en el campo del diseño gráfico.

Aquellos primeros encargos de diseño fueron realizados por artistas con su propio estilo, adaptándose a las

12 Firma de impresión alemana, principios del s. XX. 
nuevas técnicas de impresión. "La etiqueta como imagen de identidad e identificación" logra que se identifique un producto a la vez que lo distingue de otros del mismo sector, consiguiendo una eficaz identificación y diferenciación, por parte del consumidor por el simple hecho de su diseño claro y específico.

La ilustración de la etiqueta (fig. 10), siempre íntimamente asociada a los alimentos que contiene (en este caso), intenta mostrar al comprador una imagen ideal del contenido, cuya conservación requiere en algunas ocasiones que se trate de un recipiente especial y no transparente. En este tipo de etiquetas, realizadas en la industria murciana de la época, se aprecia cómo, en detrimento de la fotografía, el artista plantea una ilustración que resulta especialmente atractiva y eficaz comercialmente.

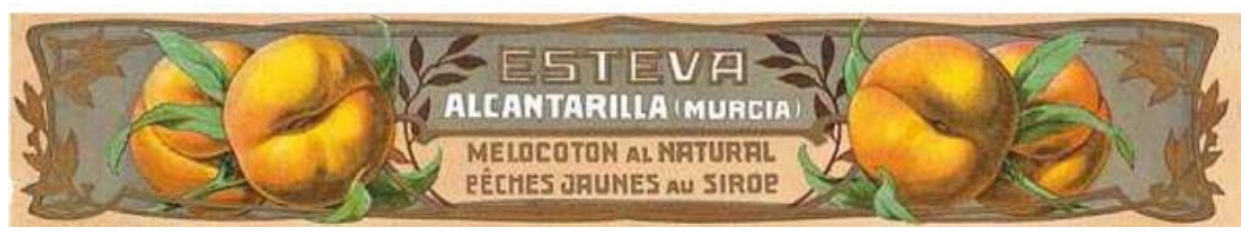

Fig. 10. Esteva. Etiqueta, h. 1910. Alcantarilla, Murcia. Litografía Hermenegildo Miralles. Alicante. 6,4 x 34cm.

En la región de Murcia la etiqueta ha sido uno de los principales motores de las artes gráficas por la importancia de los sectores económicos para los que se ha diseñado. Conservas, exportación de frutas, fabricación de chocolates y bebidas han sido sus principales destinatarios.

Hervás Avilés ${ }^{13}$

Coincidiendo con esta época se funda en Murcia Gráficas Belkrom, y de sus plantillas salen nuevas empresas como: A.G. Novografo I.G. Jiménez Godoy.

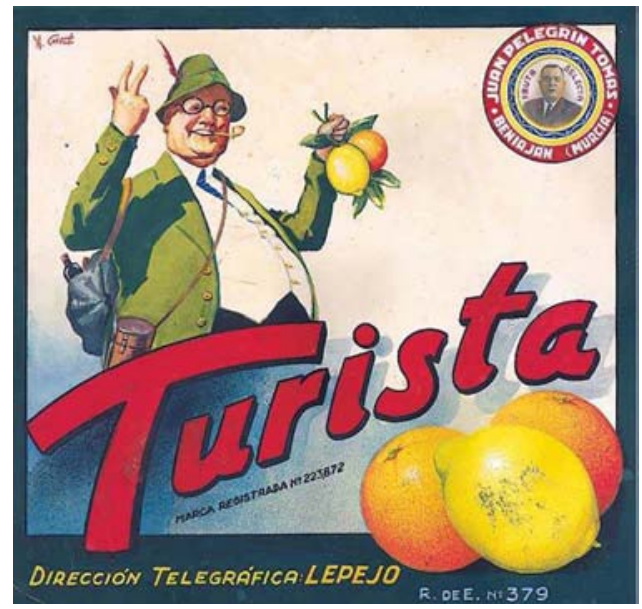

Fig. 11. A. Carot. Diseño para testero, h. 1935. Juan Pelegrín Tomás. Marca Turista. Beniaján, Murcia. Témpera sobre cartulina. Estudios Goya, Valencia. 24,5 × $26 \mathrm{~cm}$ 
Artistas como Antonio Laorden (fig. 12) diseñaron muchos de los testeros, que se realizaron en Belkrom (1960) y en la litografía de Cristóbal Pagán (1960). Es destacable su dominio del dibujo así como la característica de que siempre utiliza en su obra el personaje femenino como tema principal, mostrando una clara influencia del cartel de cine, y destacando su forma de enfocar la producción gráfica bajo una óptica publicitaria en toda regla.

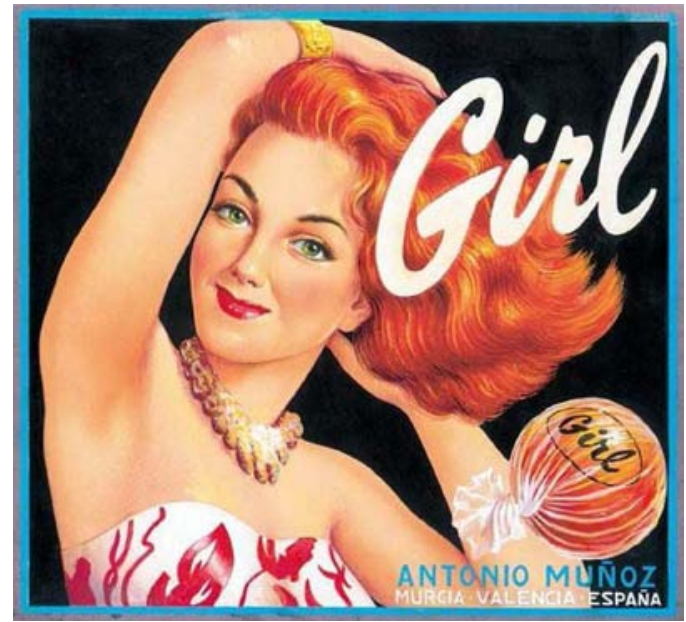

Fig. 12. A. Laorden. Diseño para Girl, h. 1960. Antonio Muñoz. Murcia. 24 x 26 cm.

\section{ARTISTAS MÁS DESTACADOS Y SUS DISEÑOS}

(...) la editorial Levante apostaba por la evasión, por lo intemporal, por lo artificial. Románticos rezagados y epígonos modernistas ensayan la continuación de movimientos periclitados. Gil de Vicario es uno de ellos.

Jiménez ${ }^{14}$

Muchos fueron los artistas que desde finales del siglo XIX y, sobre todo, a lo largo del siglo XX marcaron el ritmo en cuanto al desarrollo del diseño gráfico se refiere, en la publicidad de las empresas murcianas, dedicadas a la fruta y especias, especialmente el pimentón. A pesar de ello, debemos limitarnos sólo a algunos de ellos. Nos dedicaremos, por tanto, a algunos de los artistas más destacados en cada una de las distintas épocas en que hemos dividido el espacio de tiempo antes reseñado, es decir, de 1899 hasta principios del siglo XXI. Dicha división consta de dos partes:

- Primera mitad siglo XX (1899-1949) y segunda mitad siglo XX (1950-1999).

- Primera mitad siglo XX. (1899-1949).

La no intervención de España en la I Guerra Mundial supuso una ocasión para dinamizar la economía española debido a la necesidad de abastecerse que tuvieron las industrias de los países en conflicto, que por otra

14 JIMÉNEZ MADRID, R. Narradores Murcianos de antaño (1595-1936), Universidad de Murcia-Editora Regional, Murcia 1990, p. 404 . 
parte no podrían mantener su producción habitual de víveres y productos en general. Un factor que, al igual que otros países, supo aprovechar España y que afectó al aumento de la producción con el incremento de la exportación.

En el caso de la industria conservera murciana, exporta pulpas de fruta en conserva y pimentón a Francia, Inglaterra e incluso a Estados Unidos. Los diseños de sus etiquetas procedían de aquellas primeras litográficas e imprentas de Barcelona, Valencia, Sevilla, etc. y de las primeras empresas de dichos sectores en la región murciana. Las 'latas' de pimentón, debieron empezar a fabricarse en las litografías catalanas y casi todas las que se han conservado de la época están firmadas por litografía $\mathrm{G}$. de Andrés de Badalona.

Orlas con estilo modernista, guirnaldas, iniciales de exagerada tipografía, chicas con ligeros peinados y ataviadas con mantones, que son influencia de los carteles de principio de siglo, conviven con ilustraciones más convencionales basadas en grabados decimonónicos.

Como ejemplo gráfico de este estilo destacar la etiqueta de Nicolás Gómez Tornero (fig. 13): una etiqueta realizada en litográficas de fuera de la región, para una empresa de Murcia, con destino a la exportación. El nombre que se incorpora, "selected fruit a speciality", es reproducido con una tipografía romana, con pequeños adornos en las terminaciones de algunos caracteres, concretamente ' $A$ ' y ' $N$ '.

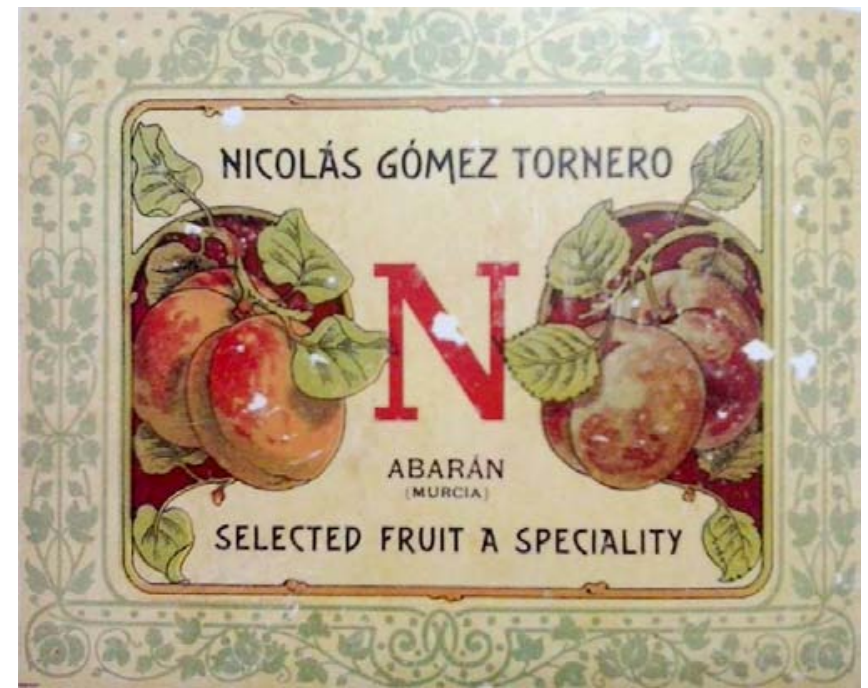

Fig. 13. Nicolás Gómez Tornero. Etiqueta, h. 1918. Nicolás Gómez Tornero. Abarán, Murcia. Litografía Hermenegildo Miralles. Barcelona. 12 x $15 \mathrm{~cm}$

Posteriormente, a partir de los años veinte, hubo una década luminosa y llena de optimismo, y de ese modo pasó a la historia. Quizás debido al firme deseo de olvidar los horrores de la guerra, la bonanza económica que supuso su fin y la recuperación económica en occidente.

Dicha prosperidad se puede asociar, concretamente en Murcia, al aumento de las exportaciones de frutas y conservas. No debemos olvidar que la aparición de los nuevos medios de comunicación, tales como el cine y la radio, supuso el fin de la ausencia de información que venían padeciendo muchas provincias españolas, entre ellas Murcia, a partir de la década de los años veinte. La moda se incorpora en los elementos reproducidos 
en el diseño, monóculos, sombreros de copa, trajes y joyas, cigarrillos en largas boquillas para las mujeres... Ello adquiere un poder de influencia en los medios publicitarios de la época y en los propios conceptos del diseño: periódicos, revistas, carteles, rótulos publicitarios, etc. donde la mujer comienza a ser la auténtica protagonista. Estas tendencias son una clara influencia de grandes capitales, como el París o Nueva York de principios de siglo.

Se trata de una época que coincide en Murcia con la apertura de los almacenes La Alegría de la Huerta (fig. 15), pertenecientes al empresario Joaquín Cerdá. Creemos importante este hecho, ya que el catálogo (fig. 14) que se edita de La Alegría de la Huerta en 1924 fue diseñado por Luis Gil de Vicario y estamos de acuerdo con Ruiz Llamas (1991), cuando afirma en su libro, que este artista fue un referente de un cambio muy significativo en el arte de la región.

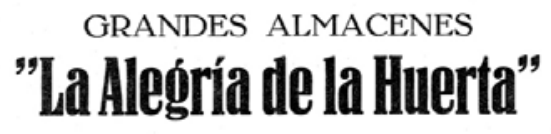

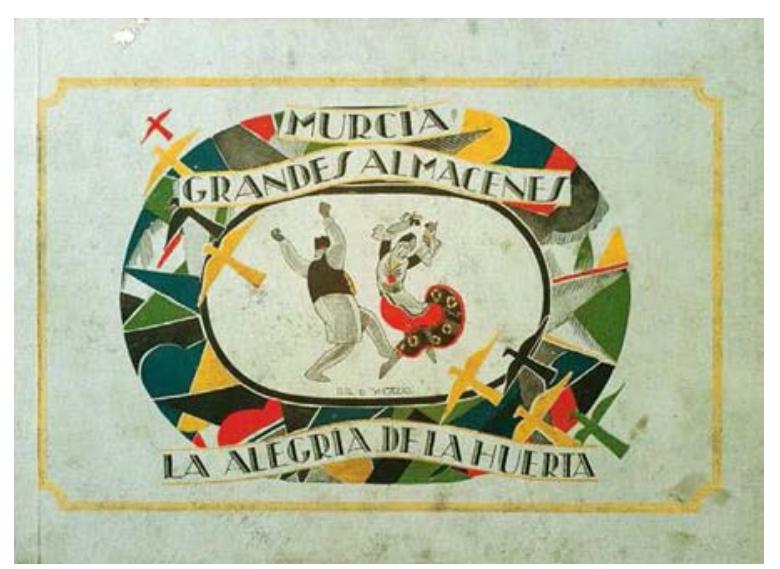

Fig.14. Catálogo de La Alegría de la Huerta. Diseñado por Gil de Vicario, 1924

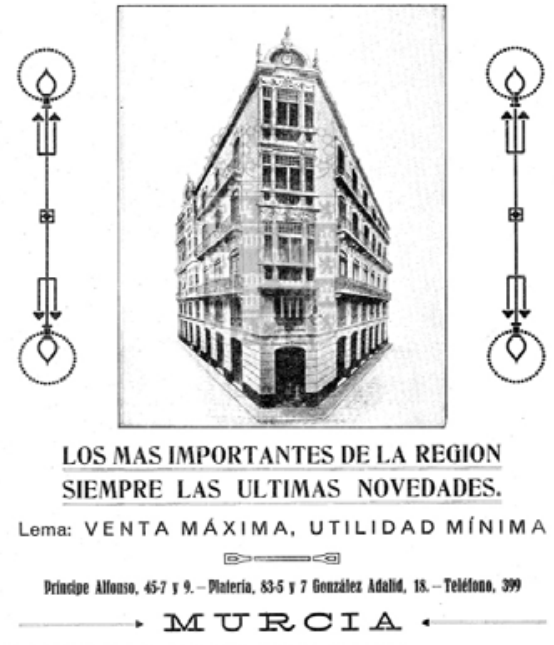

Fig. 15. Anuncio publicitario de los grandes almacenes $L a$ Alegría de la Huerta, aparecido en el extraordinario del Diario La Verdad de Murcia, 01.01.1924, pág. 28.

Nos centraremos en varios artistas: Luis Garay (1893-1956), Pedro Flores (1897-1967) y Gil de Vicario (19001959). Se trata de tres grandes artistas que nos ayudarán a ilustrar y analizar este período. Comenzaremos por Gil de Vicario, un artista muy polifacético (escritura, pintura, escultura, ilustración gráfica, etc.), aunque nos centraremos principalmente en su faceta como ilustrador gráfico. Nacido en Burgos en 1898, vino a Murcia en su juventud, con tan sólo diecisiete años. Dentro de su frenética y polifacética actividad destacan sus ilustraciones para libros (figs. 16 y 17), para la revista Estudios Médicos, realizando sólo las cabeceras y viñetas interiores a partir de 1924, así como en el extraordinario de La Verdad de Murcia, entre otros. En el caso de la revista Estudios Médicos, su participación se materializa con los anuncios de Yodofucol, donde aparece un señor con chistera y monóculo, y del Instituto Ferrán de Barcelona, donde representa a una mujer vestida con túnica griega, siendo esta última realizada con cierta alusión a la estética de la secesión vienesa. 


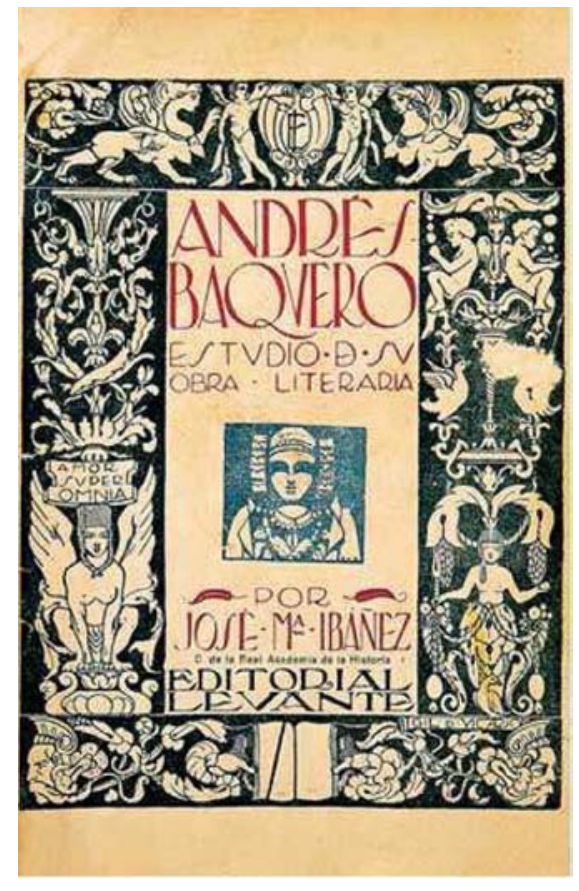

Fig. 16. Ilustraciones de Gil de Vicario para las cubiertas del libro Andrés Baquero, de José María Ibáñez (1922).

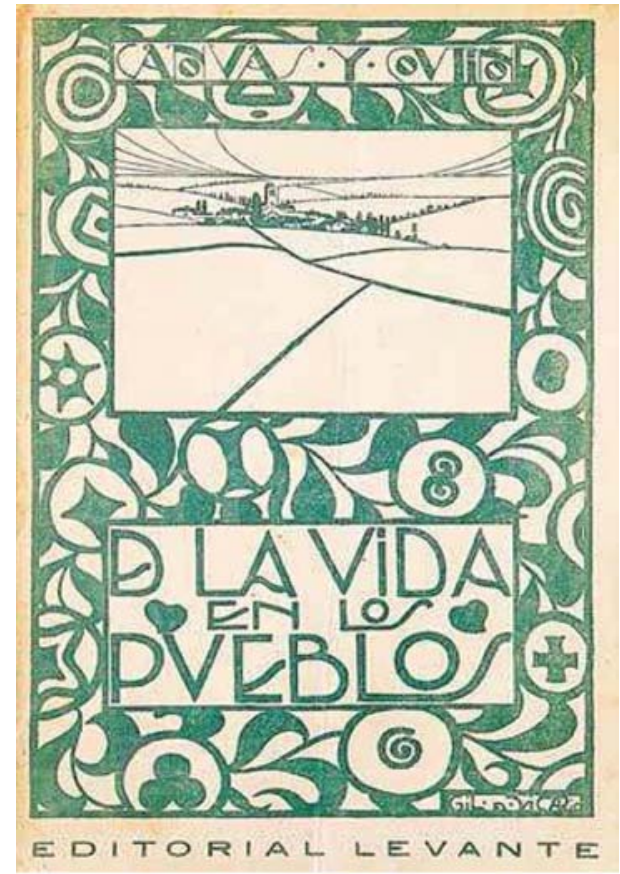

Fig. 17. llustraciones de Gil de Vicario para las cubiertas del libro La vida en los pueblos (1921).

En cuanto a la personalidad de Gil de Vicario, hay un artículo de Luis Garay donde describe brevemente al artista que ha diseñado el catálogo de Cerdá, mediante una portada que se podría considerar decó y en la que destacan los destellos dorados. En pocas palabras, lo describe como "un dandy que disfruta de los placeres de la vida", según Hervás Avilés ${ }^{15}$, Luis Garay ${ }^{16}$ lo describe así en un artículo publicado en El Liberal, en 1923:

(...) A veces lo encontramos en su yo natural sentado en la puerta del Casino quieto y recogido...con su sombrero de piel de topo y su corbata al batik. ¡Oh... esas corbatas de Vicario! ¡Por Diós, no quitárselas nunca...porque perdería mucho de su personalidad! Allí lo vemos abstraído en sus pensamientos interiores, indiferente hasta para con la copa de ajenjo que acaba de servirle el camarero...

Al igual que otros artistas de la época en Murcia, Gil de Vicario se dedicó también al diseño gráfico al tiempo que ilustraba revistas (figs. 18 y 19) y periódicos, o diseñaba portadas para revistas (fig. 20) y carteles. Del mismo modo, participó en infinidad de concursos de carteles, también de ámbito nacional, como fue el caso del vigésimotercer concurso convocado por la revista Estudios Médicos, al que se presentó junto a otros ilustradores de cierto renombre en la época como Penagos, Ribas y Bartolozzi. Ruiz Llamas (1991).

15 HERVÁS AVILÉS, J.M. op. cit. p. 29.

16 Nonduermas, Murcia, 17 de septiembre de 1893, Murcia 1956. 

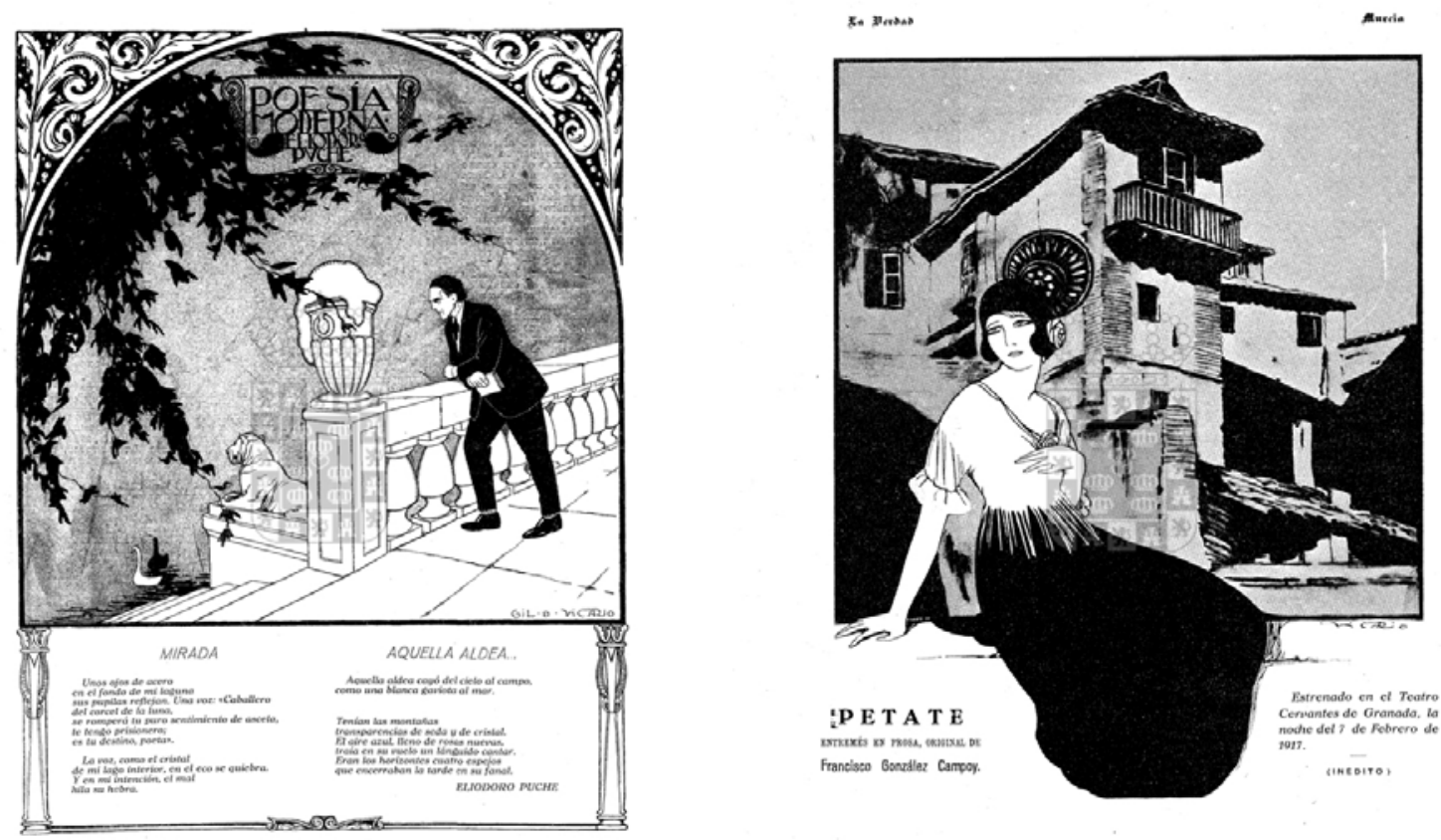

Figs. 18. y 19. Ilustraciones realizadas por Gil de Vicario en 1924, para el extraordinario del Diario La Verdad de Murcia, Murcia. 01.01.1924, pp. 39 y 74 respectivamente (Ruiz Llamas, M.G. 1991).

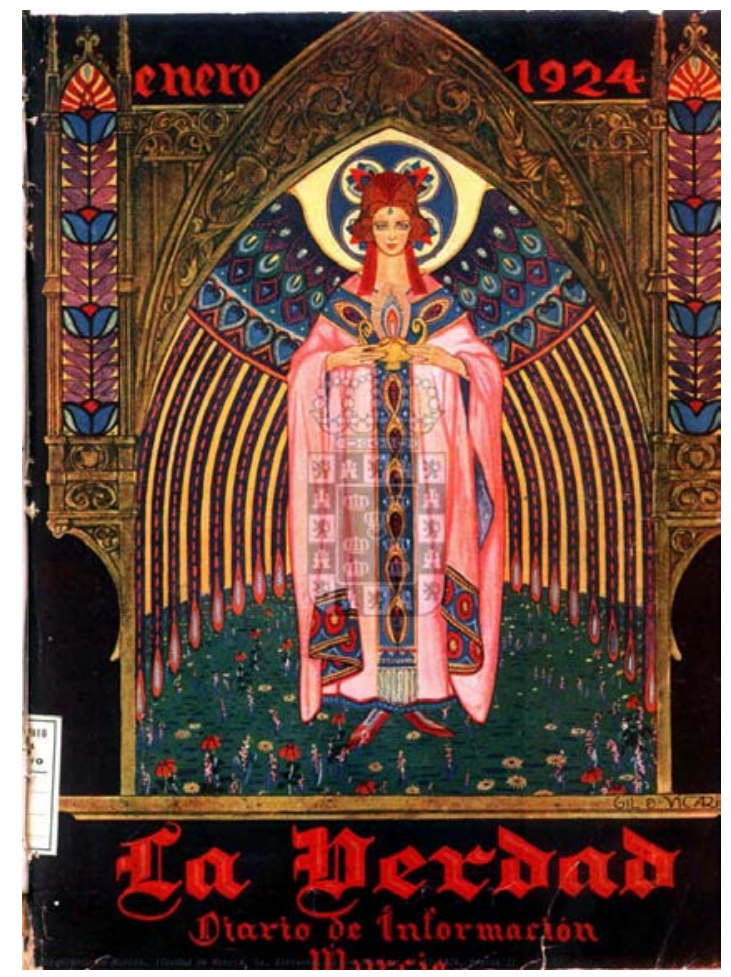

Fig. 20. Portada del extraordinario del Diario La Verdad de Murcia, Murcia. Diseñado por Gil de Vicario. 01.01.1924. 
A pesar de que Gil de Vicario residía en Murcia, viajó con mucha frecuencia a otros puntos de España, como Madrid, donde exponía y colaboró como diseñador en distintos proyectos editoriales de Atlántica ("La Novela de Hoy"), lo que permitió que estuviese al corriente de las tendencias del diseño gráfico a nivel nacional (Ruiz Llamas, M.G. ${ }^{17}$ 1991). Hemos creído conveniente comenzar por Gil de Vicario, para exponer en primer lugar un firme referente en cuanto a diseño se refiere aunque, como ya hemos comentado, no sólo se dedicó a este campo. Realmente se decantó más por el diseño e ilustración de periódicos y revistas que por el diseño gráfico de etiquetas y envases.

Un importante dibujante litográfico es Luis Garay, junto a otros artistas que se especializaron en el dibujo litográfico, como Pedro Flores ${ }^{18}$. Ambos trabajaron en ello para las primeras empresas murcianas del sector, factor al que hace clara referencia en sus memorias Pedro Flores. Concretamente muestra la época en la que comenzó su etapa de aprendizaje en el mundo de la litografía, hacia 1914, cuando comenzó a trabajar en la Litografía Alemán, una de las primeras empresas litográficas (Ruiz Llamas 1991). Dicha empresa fue denominada en primer lugar como La Artística, fundada por Carmelo Bueno para posteriormente pasar a manos de José Alemán, que compró la empresa y le cambió el nombre. En sus Memorias Pedro Flores, comenta explícitamente:

No sé ni cómo fue. Dejé el taller de Anastasio y con Garay y "el Moro" (Victorio Nicolás ${ }^{19}$ (1896-1963) fui como dibujante litógrafo a la fábrica de latas de conserva de don José Alemán, en el barrio de San Antolín (Hervás ${ }^{20}$, 1999: 65).

Sería la empresa Litografía Alemán una de las más importantes de la época, pues coincide en el tiempo con el auge del sector de la industria conservera y más concretamente pimentonera. En un anuncio de 1928, reproducido en el almanaque de la Editorial Levante, aparecen claramente anunciadas las líneas de trabajo de dicha empresa: "Cromolitografía sobre hojalata, Fabricación de envases metálicos para diversas industrias. Fábrica de conservas. Carretera de Espinardo. Murcia" (Hervás $\left.{ }^{21}, 1999: 66\right)$.

Conservas, exportación de pimentón, frutas, fabricación de chocolates y bebidas han sido sus principales destinatarios. Coincidiendo con el auge de la exportación de frutas y conservas se funda en Murcia la gráfica Belkrom.

Luis Garay perseveró más en el dibujo litográfico, y por tanto de él han quedado para la posterioridad dibujos originales que atestiguan qué diseños realizó, mientras que Pedro Flores y Victorio Nicolás se dedicaron más al retoque fotográfico de fotos ampliadas (Ruiz Llamas, M.G. ${ }^{22}$ ). Es importante señalar este punto, ya que los autores, al trabajar a sueldo como dibujantes para las litográficas, rara vez firmaban sus trabajos. La obra de

17 RUIZ LLAMAS, M.G. op. cit. p. 77.

18 Pedro Flores. Pintor murciano y dibujante litográfico. Murcia 1897-Murcia 1967.

19 Victorio Nicolás (1896-1963). Pintor murciano y dibujante litógrafo.

20 HERVÁS AVILÉS, J.M. op. cit. p. 65.

21 Ibidem. p. 66.

22 RUIZ LLAMAS, M.G. op. cit. p. 67. 
estos tres autores fue muy importante en la empresa Litografía Alemán, en lo que a dibujo litográfico se refiere, y en una época en la que esta empresa fue un claro referente con la exportación, nacional e internacional.

Hasta tal punto llegó la importancia de la litografía murciana, que exportadores y empresas dedicadas a las especias de otros países realizaban encargos a las empresas y artistas de la región. Un claro ejemplo de ello es el de Luis Garay, que realizó un trabajo para la empresa The Frank Tea \& Spice Co. de Cincinnati, Ohio (EEUU), que tenía relaciones comerciales con Murcia y encargó dibujos para la marca El Centauro (figs. 22, 23 y 24) de Espinardo, conservándose aún dibujos originales (fig. 21).

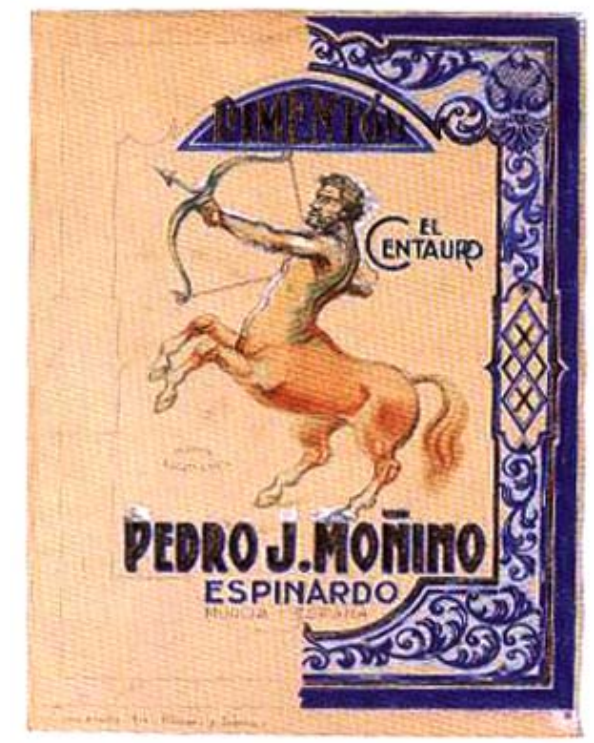

Fig. 21. Ilustración para pimentón El Centauro, h. 1925. Pedro J. Moñino. Espinardo. Murcia. Acuarela y témpera sobre papel. $19,9 \times 17,5 \mathrm{~cm}$.
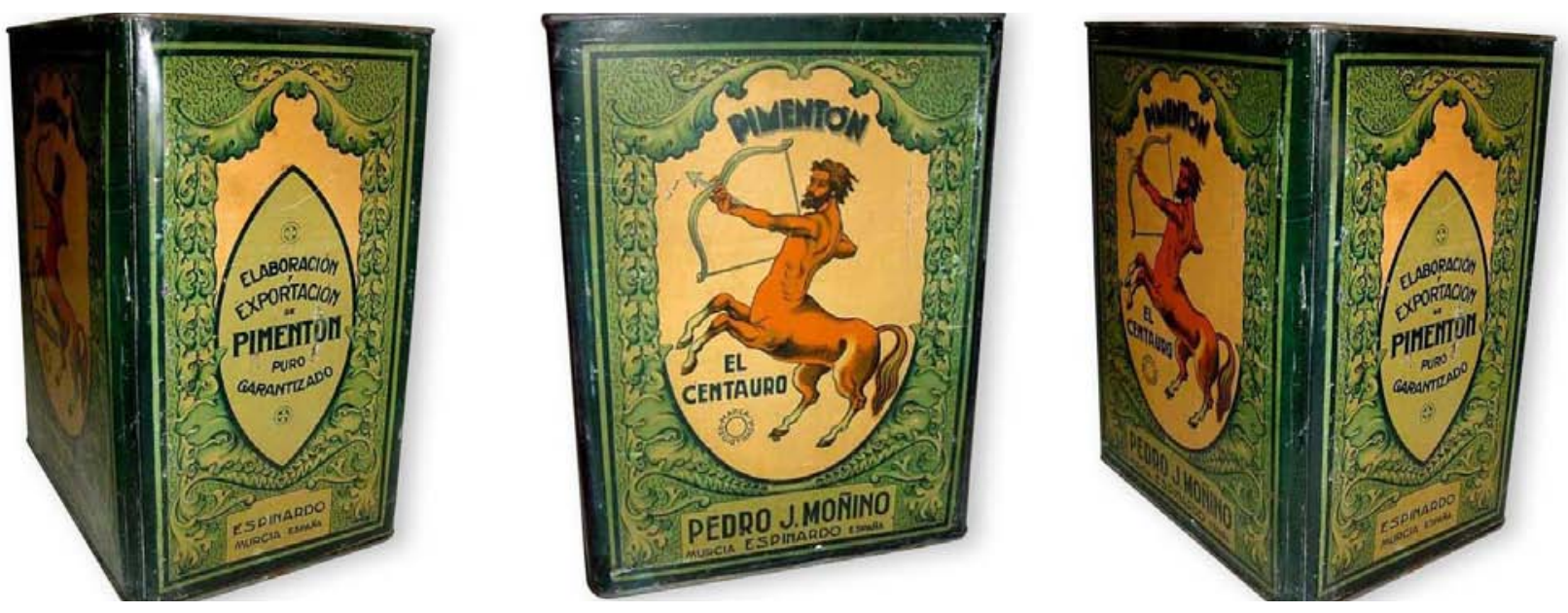

Figs. 22, 23 y 24. Vista de la lata, desde tres ángulos distintos, de la marca El Centauro, cuyo dibujo litográfico es de Luis Garay, h. 1925. Pedro J. Moñino. Espinardo, Murcia. 19,9 x 17,5 cm. 
Los últimos trabajos de Gil de Vicario en la región de Murcia están fechados en 1929, año que coincide con el crac de la bolsa de Nueva York. Este afectó muy negativamente a las economías de occidente, desembocando finalmente en la II Guerra Mundial. Este revés a la economía se vio acrecentado en España debido a la Guerra Civil. En ambos casos, los artistas lo sufrieron con especial rigor, ya que las serias dificultades económicas generaron una gran convulsión social.

El mundo de la ilustración gráfica derivó en una de sus ramas, la caricatura satírica. Muchas de las revistas de los años veinte desaparecieron para dar paso a otras nuevas con pocos números publicados, es decir, de carácter efímero la mayoría, es el caso en la región, del Diario de la República y de Ofensiva, debido a la Guerra Civil española. Ésta irrumpió en la vida cultural, y supuso un periodo de excepcionalidad que irremediablemente afectó a todo el país, en general, en todos los ámbitos de la sociedad. Dependiendo del bando en que se encontrasen, los artistas se encuadraron en gabinetes de propaganda.

Finalizada la guerra, comenzó el exilio para unos y la reconstrucción para el resto. La década de los cuarenta fue una etapa difícil, porque la industria había quedado desmantelada y lo que supuso este hecho en la decadencia de la economía. Ésto, cómo es lógico, afectó notablemente al mudo del diseño y al propio planteamiento de las empresas con respecto a él. Los ilustradores y diseñadores vieron reducidos en muchos casos sus diseños para ayuntamientos y delegaciones del gobierno, que encargaban la realización de programas de fiestas y carteles.

A la escasez de medios y de trabajo se suma un factor muy notable, como fue la censura, y bajo la cual tan sólo unos pocos podían desarrollar su obra; los artistas e ilustradores que durante la contienda habían estado del lado perdedor ahora tuvieron que exiliarse, como afirma Ruiz Llamas, M.G. ${ }^{23:}$ "Garay y Almela Costa se quedan Planes se va a Madrid, Joaquín también marcha, se reafirman valores como Molina Sánchez y aparecen, ya formados, Manuel Muñoz Barberán y Mariano Ballester".

Las dificultades económicas generan una fuerte conflictividad social. Esta situación influye notablemente en el campo de la edición, impresión y el diseño gráfico en general. A partir de mediados de los cuarenta, la industria empezó levemente a repuntar, y paralelamente aumenta el consumo de conservas durante el período de la II Guerra Mundial. Cabe destacar que aumentó la producción de conservas en envase de cristal frente al tradicional de hojalata, debido a que la mayoría de la producción de estaño estaba en países asiáticos bajo dominio japonés durante la guerra. Por este motivo aumentó la exportación de conservas a potencias en conflicto, tales como Inglaterra.

En el sector conservero tomó auge el pimentonero, que gozó de gran importancia, proyectándose internacionalmente, fe de ello lo da Luis Garay en su libro: Una época de Murcia (Garay $\left.{ }^{24}, 1977\right)$, donde narra el trabajo de la empresa Litográfica de J. Alemán, exponiendo una amplia visión de la primera mitad del s. XX, publicado en los años cincuenta, e informa del trabajo de dicha empresa en los cuarenta años previos:

3 Ibidem, p. 120

24 GARAY, L. Una época de Murcia (Mi vida hasta los 58 años y otros escritos), Ed. Francisco Alemán Sainz. Academia Alfonso X el Sabio, Murcia 1977. 
La litografía de J. Alemán ha surtido de envases durante los últimos cuarenta años a la exportación de pimiento molido y buena parte de los dibujos o marcas fueron hechas por Victorio Nicolás, Pedro Flores y principalmente por mí...

Hervás ${ }^{25}$

Esta reactivación surge en todas las provincias y hace que el mundo del diseño de la etiqueta pueda recuperarse, como es el caso curioso de la creación de la primera etiqueta de Cola-Cao, realizada por el artista catalán Antonio Tusell en 1946 (fig. 25).

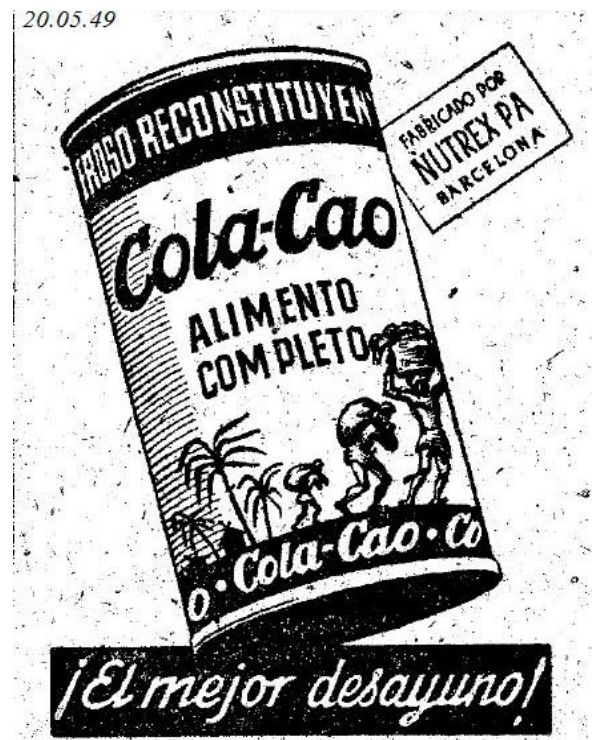

Fig. 25. Uno de los primeros anuncios publicitarios de Cola-Cao (1949)

\section{Segunda mitad siglo XX}

En la segunda mitad del siglo XX destacamos en Murcia la Feria Provincial de Muestras (fig. 27), que convocó la Cámara de Comercio de la región con el fin de promocionar el sector industrial y con una clara dinamización, en concreto en el panorama regional del diseño, durante casi dos décadas (fig. 26).

Los años sesenta supusieron un importante punto de inflexión en el desarrollo de una modernidad que se refleja en nuevas técnicas en los sistemas de impresión, aspectos que con gran éxito recogen los artistas. En este periodo hemos querido comenzar mencionando la Feria Provincial de Muestras, pues creemos que fue un importante hito para comenzar este segundo punto. 


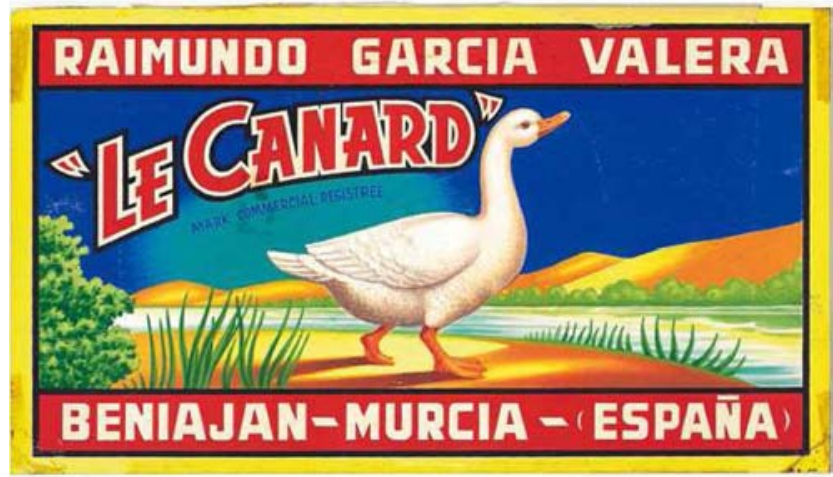

Fig. 26. Le Canard. Dibujo original para etiqueta, témpera, h. 1950. Raimundo García Valera. Beniaján. Gráficas Belkrom. Murcia. 13,8 x 24,1 cm

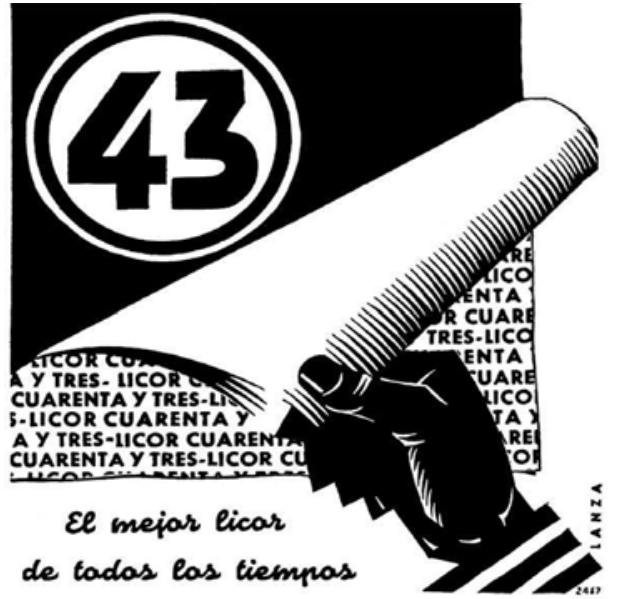

Fig. 27. Lanza. Anuncio 1956. Licor 43. Cartagena. Catálogo de la FICA. 11 x 11,7 cm.

Fruto de esa nueva actividad económica surgieron nuevas empresas en la región, entre ellas cabe destacar el nacimiento de Gráficas Belkrom, como se ha dicho anteriormente, dedicada al diseño y fabricación de etiquetas destinadas a la exportación. Entre algunos de los artistas que ilustraron las etiquetas de conserva de esta empresa destacaremos al ilustrador murciano Antonio Laorden. Este artista creó infinidad de diseños para las empresas regionales dedicadas a la exportación de frutas y hortalizas, entre 1955 y 1970 (fig. 28). Sus imágenes eran potentes y claramente influenciadas por el mundo del cine de la época (fig. 29), tratándose en la mayoría de ocasiones el personaje femenino como tema principal de la composición (fig. 30).

En sus diseños se puede apreciar un claro dominio del dibujo y la composición, muy similares los carteles profesionales de cine de la época.

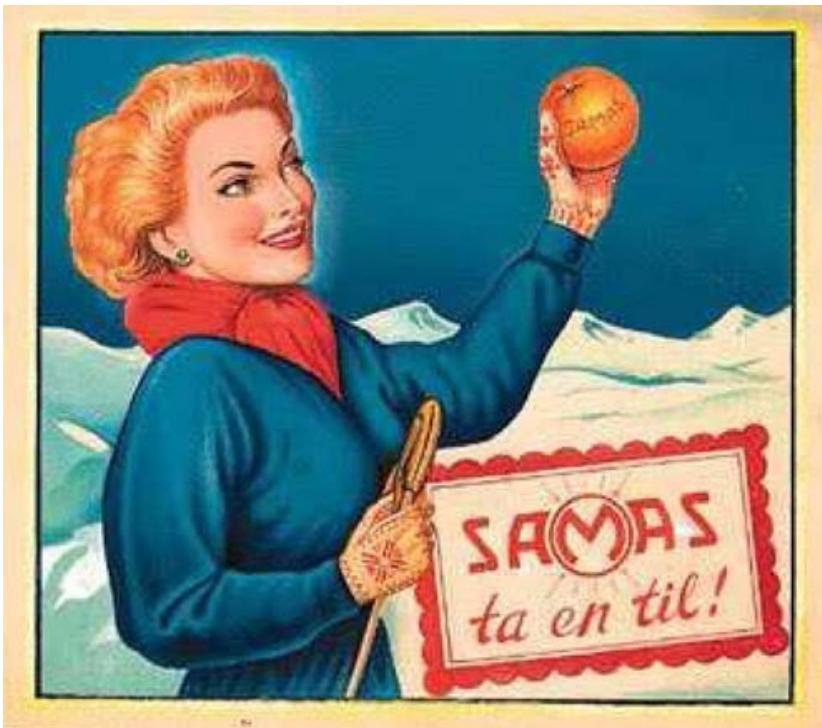

Fig. 28. A. Laorden. Diseño para Samas, h. 1955. Témpera sobre cartulina. 25,5 x 28,6 cm. 

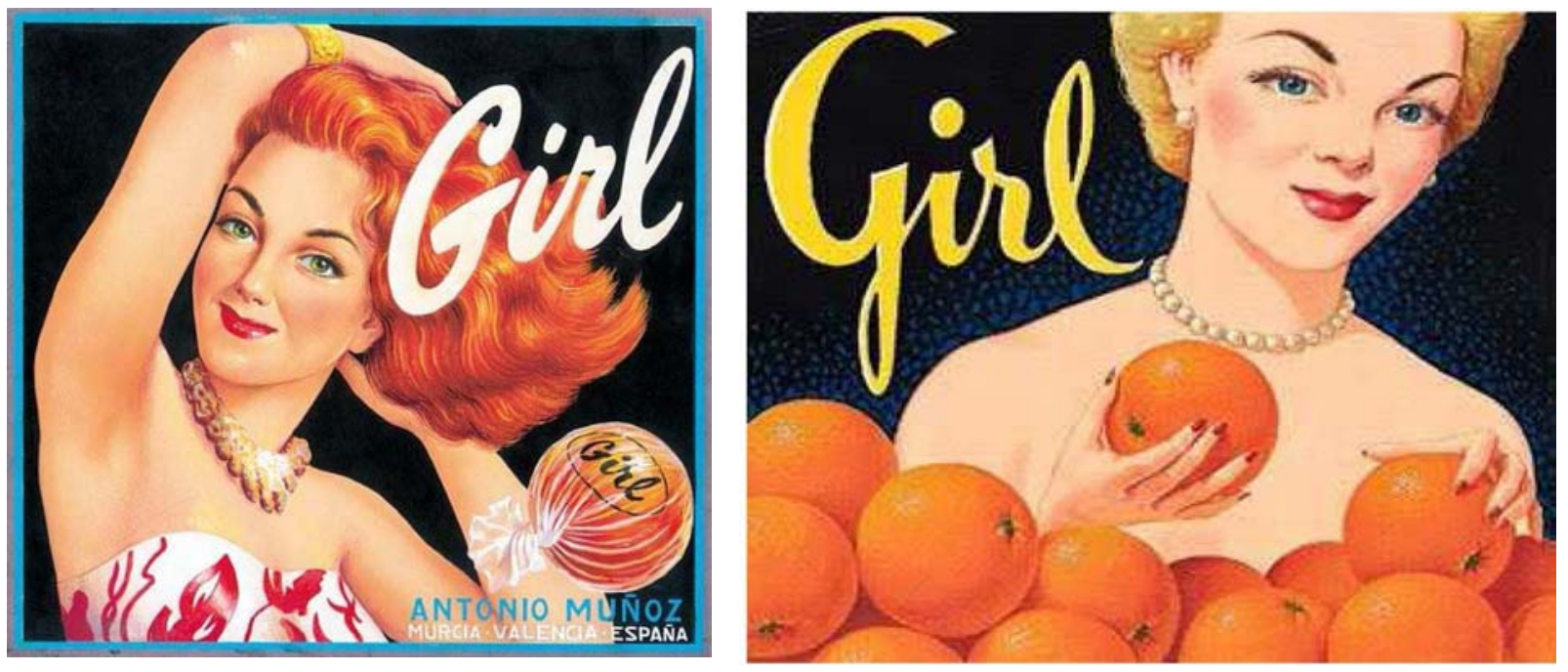

Figs. 29 y 30. A. Laorden muestra en ambas etiquetas un personaje femenino, claramente influenciado por el cine de la época, en este caso actrices de la gran pantalla. Diseño para Girl, h. 1960. Antonio Muñoz. Murcia. 24 x 26 cm. Diseño para Girl, h. 1960. Témpera sobre cartulina. 24 x $27,5 \mathrm{~cm}$.

Si en la primera mitad del siglo XX los artistas gráficos dejaban su impronta, es decir, su firma en sus diseños, ahora las nuevas empresas contratan diseñadores en sus plantillas, donde por ende, sus trabajos quedan en el anonimato. Los diseños así son adquiridos con todos sus derechos por la empresa y es ésta la que los hace circular por imprentas de la región, propiciando de este modo una clara uniformidad en cuanto al diseño de etiquetas.

En esta época, los exportadores demandaban propuestas creativas a los pintores e ilustradores para las dos tipologías gráficas que generó la exportación de fruta fresca: el papel de seda para agrios (cítricos) y el testero para las cajas de fruta (fig. 31), que eran grandes etiquetas impresas en la propia caja, que identificaban a la empresa en la caja de madera en que se transportaban las frutas $y / u$ hortalizas.

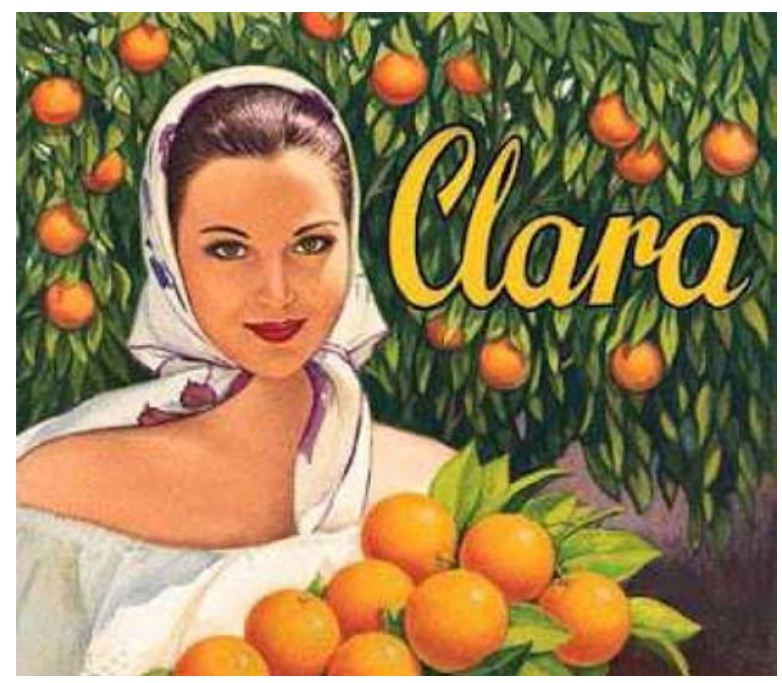

Fig. 31. A. Laorden. Diseño para Clara, h. 1955. Témpera sobre cartulina. 24 x 26,8 cm. Diseño para testero. 
A principios de los años setenta se produce un antes y un después, anterior a 1975 el arte estaba bajo la 'autorización' de la censura y posteriormente se abre a influencias europeas. Quien definió muy bien lo que supuso el diseño en este momento fue el historiador Valeriano Bozal (citado en Fernández ${ }^{26)}$ ): “(...) quizá sea el diseño gráfico el que de un modo más decisivo ha contribuido a cambiar la imagen de nuestro medio, haciendo de él, como algunos dicen, un medio más europeo".

A finales de los setenta y principios de los ochenta fue el diseño gráfico el que se transformó en la imagen de una renovación en distintos ámbitos sociales: periódicos, editoriales, empresas, entidades financieras, partidos políticos, asociaciones culturales y deportivas $y$, sobre todo, las renovadas administraciones y servicios públicos, ayuntamientos democráticos en su mayoría. Se centró el diseño en la renovación de la imagen pública, emulando a los países democráticos de nuestro entorno. Debido a estos factores tan relevantes en el diseño gráfico, cabe destacar la afirmación de Enric Satué (citado en Fernández²7): "el diseño ha sido un hijo predilecto de la democracia, y el gobierno de la nación ha dado pruebas evidentes de su preferencia".

Diseñadores como Cruz Novillo rediseñaron el logotipo del PSOE (1977), así como la identidad del Cuerpo Nacional de la Policía (1986); Alberto Corazón trabajó para las grandes empresas públicas tales como: MOPU (1978) y Telefónica, entre otras. Frente a los profesionales, que en la primera mitad del siglo XX eran autodidactas, los nacidos en la postguerra, gracias a su acceso a la universidad y otros estudios profesionales, conforman una nueva generación. Ahora ya son técnicos de comunicación y expertos en tratamiento de la imagen, aspectos que implican un dominio o conocimiento de la tipografía y la fotografía, entre otros conocimientos, que les vinculan con las nuevas corrientes artísticas.

En cuanto a la región de Murcia, se podría decir que fue la época dorada del diseño gráfico, en la que surgen premios de fotografía, concursos de diseño, y concretamente en esta región nacen Contraparada, y la Editora Regional de Murcia, que potencian los espectáculos de teatro y música, para los cuales se necesitaron nuevos diseños e ideas para sus carteles. Multitud de pintores y arquitectos apostaron por dedicarse al diseño gráfico, y las imprentas, que en su mayoría habían quedado desfasadas, se reinventan, con nuevas maquinarias y con nuevas ideas traídas por los diseñadores. Ideas que configuran un impulso de la calidad del diseño, en el ámbito de todo el país, gracias a la difusión de los proyectos que se realizan en las principales ciudades y que están en plena sintonía con el diseño internacional. Dentro de este contexto, artistas y diseñadores se asocian con el fin de dedicarse profesionalmente al diseño, formando colectivos como El Dibujador o Ekipo. Estos dos colectivos lo integran los artistas Severo Almansa, Antonio Ballester, Vicente Martínez Gadea, y Chipola.

Otros artistas de la región aportaron diseños, cómo es el caso de Salvador Romera, Javier Alberdi, López Guzmán, Giménez del Pueblo, Ángel Haro, Francisco Salinas, y Ángel Fernández Saura.

La década de los ochenta sería un interesante tema monográfico que abordaremos en otro trabajo. El libroescultura para la I Bienal de 1986 y las ediciones $7^{\underline{a}}$ y $9^{\underline{a}}$ de Contraparada, dedicadas a Bonafé y Canogar

26 FERNÁNDEZ, H. (Comisario exposición). Fotos \& libros. España 1905-1977, Ed. Horacio Fernández. Museo Reina Sofía, Madrid 2014, p. 66.

27 Ibidem, p. 68. 
(figs. 32 y 33), son otras aportaciones a destacar junto a la creación del símbolo institucional de la Región de Murcia y el cartel para la segunda celebración de las Jornadas de Diseño, que son ejemplos de la madurez que Murcia adquiere en el ámbito del diseño.

Será finalmente en los noventa cuando, gracias a la Exposición Universal de 1992 en Sevilla, y la Olimpiada de Barcelona, el fenómeno del diseño gráfico en España creció notablemente, de modo paralelo en la Región de Murcia, y tuvieron una especial difusión y valoración a nivel internacional. También fueron tiempos en los que, además de pintores y arquitectos, los informáticos formados en las escuelas de arte se unen al mundo del diseño gráfico con la aparición del Macintosh para la autoedición digital del diseño. Este amplio abanico de especialistas repercutió en una reconversión del proceso de producción gráfica en los noventa: Martínez Mengual, Manuel La Rosa o Pedro Manzano, entre otros, muchos de los cuales aún siguen en activo a día de hoy.
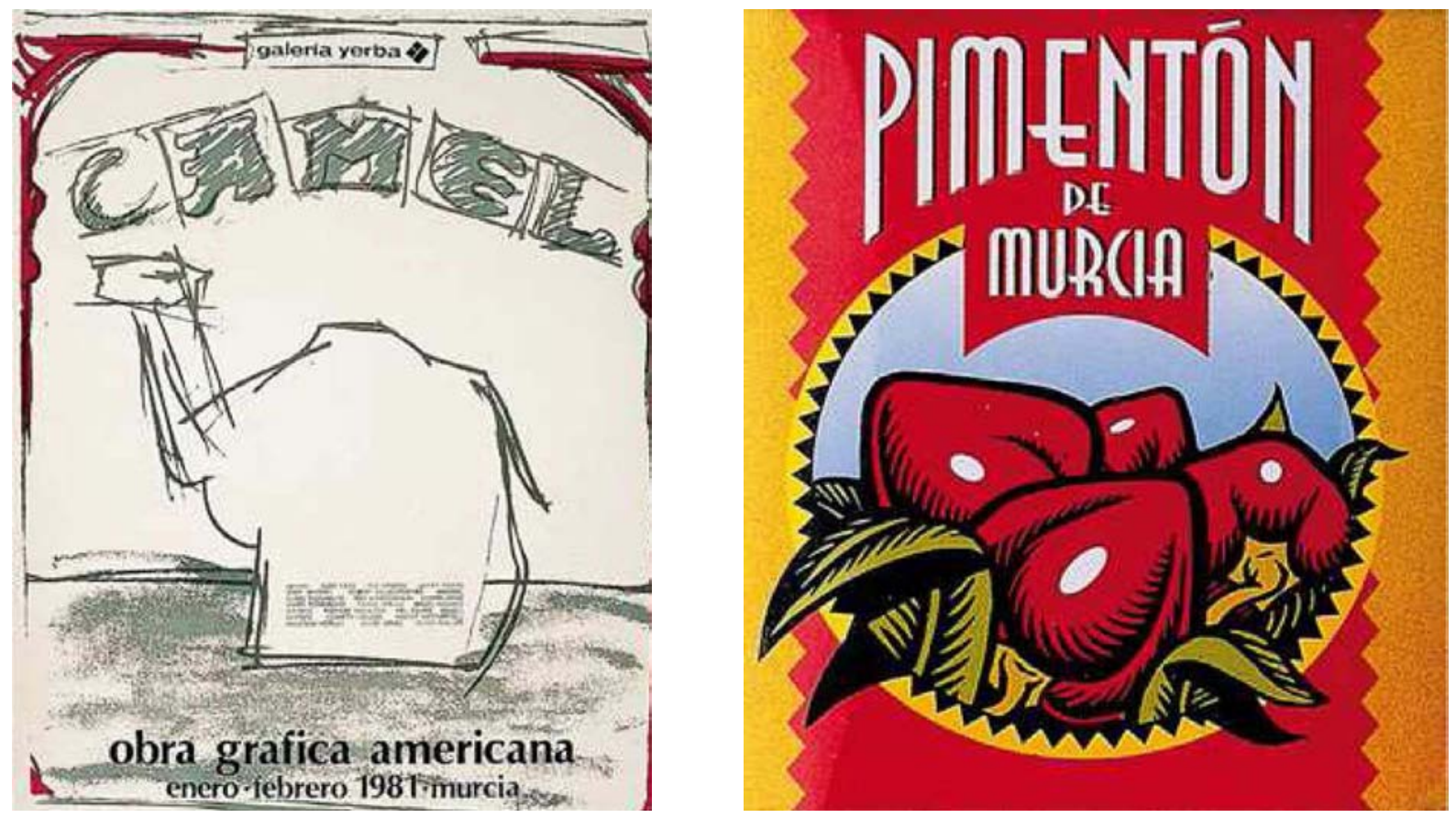

Figs. 32 y 33. Cartel para la exposición Obra Gráfica Americana, diseñado por Juan Antonio Molina, 1981 (izquierda). Caja de cartón diseñada por Eduardo Saro, 1988 (derecha).

Es importante, para acabar este apartado, destacar a un autor a nivel nacional, Cruz Novillo ${ }^{28}$ (Cuenca, 1936), puesto que consideramos que, sin restar importancia al resto de diseñadores de su época, aúna en su obra, no sólo la tendencia cambiante de finales del siglo XX, sino también el cambio que supuso en España el inicio de la democracia, y más concretamente la transición. Dicha importancia se debe, como decíamos, a los cambios que aportó en la vida pública y estatal española, en lo que al diseño gráfico se refiere. Cruz

28 Pepe Cruz Novillo es uno de los nombres más relevantes en el grafismo español, fundamental en el campo de los pioneros del diseño moderno desde la creación de marcas (Repsol, Renfe, El Mundo, PSOE, Correos...) a carteles para películas, con su síntesis del "diseñar es crear" y con los más prestigiosos premios al diseño y a la pintura concedidos en España (LAUS en 1978, Premio Nacional de Diseño en 1997, Premios AEPD 1993, 1995, 1996 y 2001, Medalla del FAD en 2006 o Medalla de Oro al Mérito en las Bellas Artes en 2012). 
Novillo renovó imágenes gráficas estatales, como Correos y Telégrafos (fig. 34), mediante una síntesis de los atributos universales de este referente, y renovó numerosos símbolos comunes de la vida diaria de ese momento, acordes con el espíritu de la transición, al tiempo que modernizaba también el diseño de billetes de curso legal. Por tanto, no sólo es un referente a nivel gráfico, por sí solo, sino también porque marcó un hito en el diseño gráfico de ese periodo histórico de la transición (fig. 35).

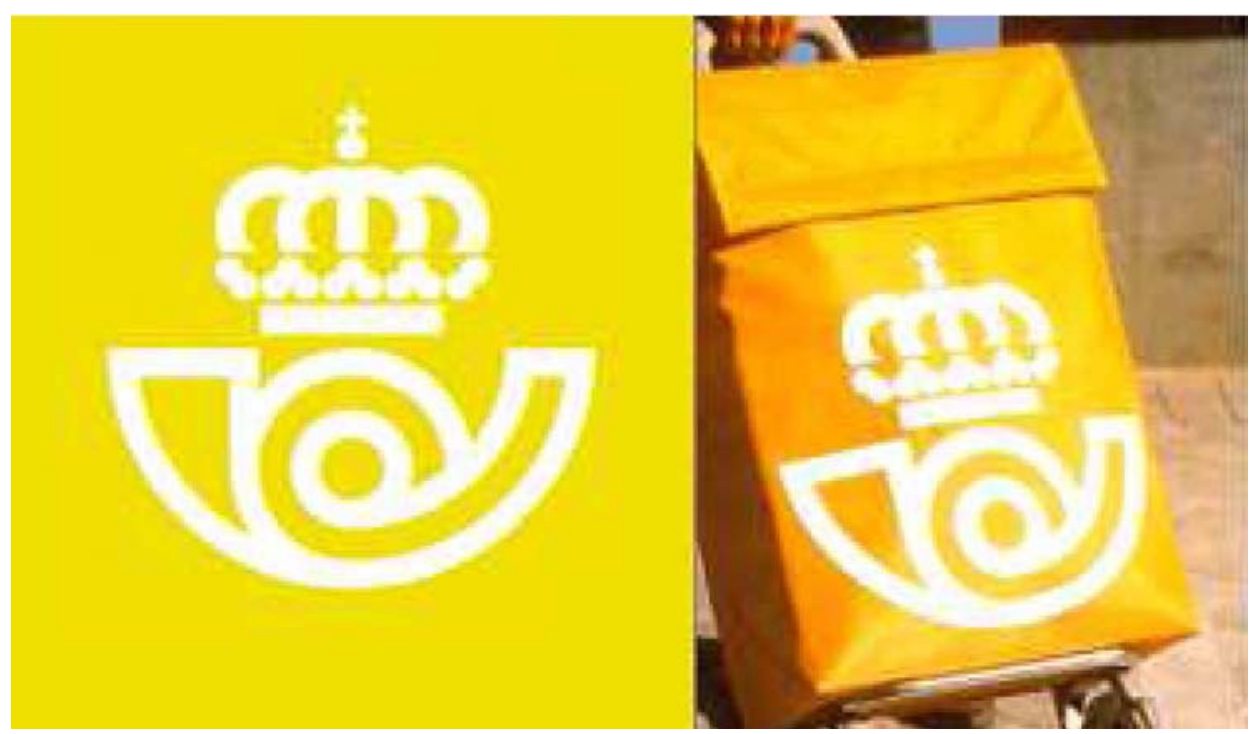

Fig. 34. Rediseño logotipo Correos y Telégrafos. Cruz Novillo (1975).
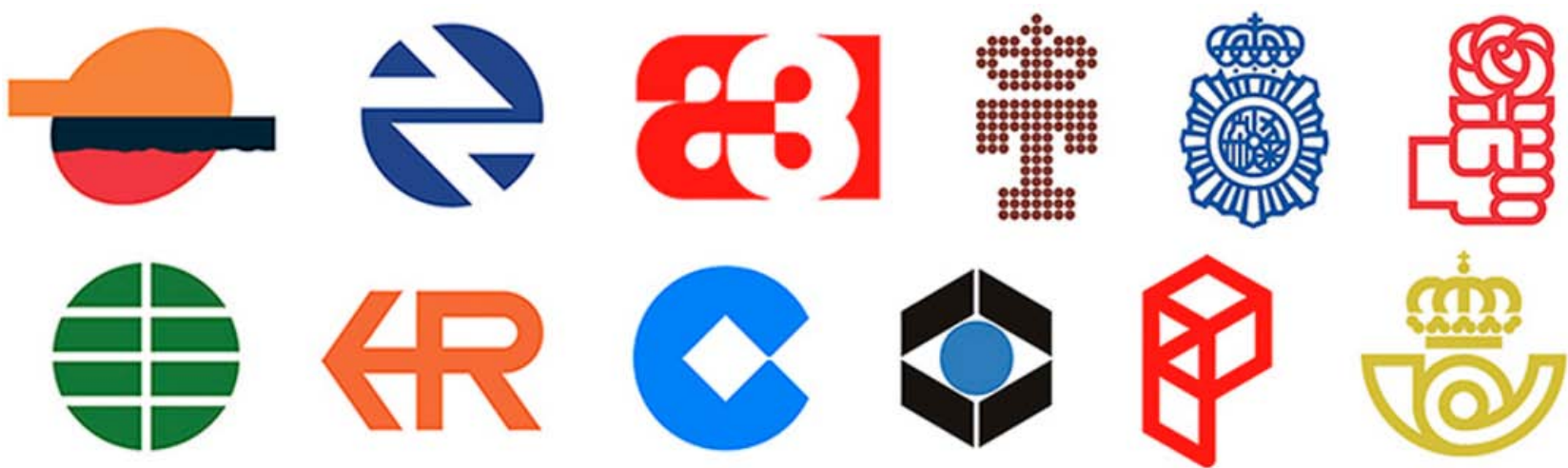

Fig. 35. Diseños de Cruz Novillo: Repsol, Renfe, Antena 3, Tesoro Público, Cuerpo Nacional de Policía, PSOE, EI Mundo, Cope, Correos, etc.

\section{CONCLUSIÓN}

En primer lugar, señalar que, mediante el estudio de las empresas y los diseñadores de esta región de Murcia, hemos podido acceder a datos e imágenes que en muchos casos estaban desaparecidos o simplemente olvidados, recuperando la historia de ese ayer, desde la observación y estudio del diseño y los artistas gráficos locales, en el ámbito nacional-internacional, prácticamente desde principios del s. XX hasta hoy. 
El descubrimiento del extravío o desecho de envases, fotografías, o simplemente documentos que eran historia viva -de los que se tiene constancia por transmisión oral- y que por descuido o negligencia, han desaparecido, han sido unos de los mayores inconvenientes, por su dificultad, en la revisión del diseño gráfico de etiquetas de la industria conservera murciana, especialmente la pimentonera.

Con ello, hemos pretendido contribuir al rescate de este patrimonio histórico que supone el diseño gráfico en Murcia, pues para una Región pionera en la conserva es vital el reconocimiento de estas litografías presentes en la decoración e identidad visual corporativa de las latas de pimentón. El trabajo abordado es una breve aportación sujeta a las características de un artículo, ya que la recopilación de material es mucho más extensa y profunda.

Las características más generales que podemos encontrar serían:

- La regularidad del formato de las latas (prismas rectangulares y cubos) permite realizar sobre sus caras composiciones de diseños equilibrados en su dibujo y policromados.

- El diseño gráfico en la empresa murciana es estilísticamente 'anárquico', a priori, puesto que en muchos casos deriva de la consecución y adaptación de tipografías y tendencias artísticas, que recogen en muchos de sus diseños, para llegar a un diseño propio, en constante revisión por sus diseñadores.

- En un principio, la influencia más destacada tiene una estética modernista propia de las Artes Industriales y Decorativas del momento, no purista.

- Empleo de motivos decorativos -orlas, cenefas y guirnaldas- combinados con tipografías a fin de producir una mayor atracción visual.

- Dibujos de una cuidada y variada tipografía, adaptadas al producto y la empresa, de ordenada caligrafía en torno a un motivo central.

- La temática religiosa corresponde a un espíritu cristiano centrado en las imágenes de vírgenes y santos bajo cuya advocación se encomienda la empresa.

- La temática profana es diversa, por un lado hace referencia a temas populares de carácter costumbrista y, por otro, a figuras mitológicas y simbólicas de origen clásico.

- La marca concebida como monograma -juego de iniciales- es trazada artísticamente, a modo de emblema nobiliario, situándose entre decoración floral y geométrica.

- Perdurabilidad de muchos de estos diseños a lo largo del pasado siglo XX e incluso algunos hasta nuestros días. 


\section{REFERENCIAS}

CÁNOVAS CANDEL, F. Santomera y los Pimientos, Edición particular, Murcia 1996.

CERVERA FANTONI, A.L. Envase y embalaje. La venta silenciosa. (2ª ed.), ESIC, Barcelona 2003.

DEL RÍO FERNÁNDEZ, P. Litografía, creación y producción para la gráfica de los frutos selectos de Málaga (tesis doctoral), Universidad de Málaga, 2010.

FERNÁNDEZ, H. (Comisario exposición) Fotos \& libros. España 1905-1977, Ed. Horacio Fernández. Museo Reina Sofía, Madrid 2014.

GARAY, L. Una época de Murcia (Mi vida hasta los 58 años y otros escritos), Ed. Francisco Alemán Sainz. Academia Alfonso X el Sabio, Murcia 1977.

HERVÁS AVILÉS, J.M. Diseño Gráfico en Murcia (1899-1999), Ed. Cámara Oficial de Comercio, Industria y Navegación de Murcia, Murcia 1999.

JIMÉNEZ MADRID, R. Narradores Murcianos de antaño (1595-1936), Ed. Universidad de Murcia-Editora Regional, Murcia 1990.

RUIZ LLAMAS, Mạ.G. La ilustración gráfica en periódicos y revistas de Murcia: 1920-1950, Universidad de Murcia, Murcia 1992.

SATUÉ, E. El diseño gráfico en España. Historia de una forma comunicativa nueva, Alianza Editorial, Madrid 1997.

SALOMA RAMíREZ, M.E. Historia del Diseño Gráfico, London University, México 2006. 